Université กhn
de Montréal

Serge Sultan, Université de Montréal

How to cite this article:

Burns, W., Péloquin, K., Sultan, S., Moghrabi, A., Marcoux, S., Krajinovic, M., Sinnett, D., Laverdière, C., \& Robaey, P. (2017). A 2-year dyadic longitudinal study of mothers' and fathers' marital adjustment when caring for a child with cancer. Psycho-Oncology, 26(10), 1660-1666. doi:10.1002/pon.4189

DOI: $\quad$ https://doi.org/10.1002/pon.4189

PMID: $\quad 27278682$ 
A two-year dyadic longitudinal study of mothers' and fathers' marital adjustment when caring for a child with cancer

Burns, W. . ${ }^{1,3}$, Péloquin, K. ${ }^{1}$, Sultan, S. ${ }^{1,2,3}$, Moghrabi, A. ${ }^{3}$, Marcoux, S. ${ }^{2,3}$, Krajinovic, M. $^{2,3}$, Sinnett, D. ${ }^{2,3}$, Laverdière, C. ${ }^{2,3}$, Robaey, P. ${ }^{3,4,5}$

${ }^{1}$ Department of psychology, Université de Montréal, Montréal, Québec, Canada.

${ }^{2}$ Department of pediatrics, Université de Montreal, Montréal, Québec, Canada.

${ }^{3}$ Sainte-Justine University Health Center, Montréal, Québec, Canada.

${ }^{4}$ Children's Hospital of Eastern Ontario, Ottawa, Ontario. Canada.

${ }^{5}$ University of Ottawa, Ottawa, Ontario, Canada.

Corresponding author:

Serge Sultan

Sainte-Justine UHC

3175, Chemin de la Côte-Sainte-Catherine

Montréal H3T 1C5

Québec, Canada

serge.sultan@umontreal.ca

tel. + 1 (514) 343-6111 ext. 20727 


\title{
A two-year dyadic longitudinal study of mothers' and fathers' marital adjustment when caring for a child with cancer
}

\begin{abstract}
Objective: Studies examining interrelationships within parental couples confronted with pediatric cancer are scarce. This study explored dyadic longitudinal associations between both partners' family functioning and mood at diagnosis, and marital adjustment two years later.

Method: Parents of children ( $n=47$ couples) with acute lymphoblastic leukemia (ALL) completed the Family Well-Being Assessment and Profile of Mood States-Bipolar Form at diagnosis, and the Locke-Wallace Marital Adjustment Test two years post diagnosis. Multilevel linear models using the actor-partner interdependence model (APIM) and controlling for baseline marital adjustment were conducted to evaluate within subject and dyadic longitudinal effects.

Results: For mothers, better marital adjustment two years post diagnosis was associated with perception of greater family support and less role conflict and role overload at diagnosis. For fathers, better marital adjustment two years post-diagnosis was associated with perception of less role conflict, greater role ambiguity, and being more tired at diagnosis, as well as their partner's perception of less role conflict at diagnosis.

Conclusions: These findings highlight the importance of considering both partners' perspectives in understanding marital adjustment across treatment phases in parents of children with ALL. Early interventions for couples should be tailored to meet each partner's needs in order to foster resilience within the couple.
\end{abstract}

Keywords: pediatric cancer; parents; oncology; marital adjustment; family functioning; APIM 


\section{A two-year dyadic longitudinal study of mothers' and fathers' marital adjustment when caring for a child with cancer}

\section{Introduction}

The diagnosis of a pediatric cancer is undoubtedly a difficult time for parents. The demands associated with the child's illness and treatment can lead to changes in family dynamics, roles, and responsibilities [1], and may also bring challenges for the marital relationship [2]. While confronted with the threat of their child's death, parents are called to make crucial and difficult decisions about their ill child's treatment and care. Parents' reactions to diagnosis and their ability to readjust their roles effectively in the face of cancer will likely influence both their own adjustment and their child's adjustment $[2,3]$. Although the effects of pediatric cancer on parents' individual functioning have been widely cited [1,3-5], research on the impact of cancer on their conjugal functioning has received limited attention $[2,6,7]$. This research also generally has important limitations, including the use of cross-sectional designs and reliance on using an individual perspective to explain marital outcomes instead of formal dyadic approaches considering both partners' perspectives. Dyadic studies examining predictors of long-term marital adjustment in the context of pediatric cancer are thus needed. The parental couple is a fundamental component within the family system that could potentially serve a protective function for both the ill child and the family. Understanding the factors associated with better relationship adjustment over time therefore appears crucial.

The handful of studies that have examined the impact of pediatric cancer on marital functioning have yielded mixed results. Quantitative and qualitative studies found that while some couples report a negative impact of their child's illness on their relationship, others report relatively little change or a positive impact, including improved support, trust, and communication [7-9]. However, this dichotomous classification into positive and negative relationship changes is likely not representative of the intricate and evolving nature of the cancer experience. Caring for a child with cancer can affect parents' life as a couple and the quality of the relationship may follow a temporal adaptation process, reflecting particularities of stages in the cancer trajectory. Past cross-sectional studies suggest that marital quality follows a curvilinear course as a function of illness duration $[7,10]$. Near the time of diagnosis, parents tend to report heightened marital dissatisfaction and distress [11-13]. Research found that among couples whose child was newly diagnosed, $25 \%$ of mothers and $28 \%$ of fathers had clinically significant marital distress scores [11]. This initial marital distress and dissatisfaction would endure throughout the first year following diagnosis, as indicated by both cross-sectional [7] and longitudinal studies [12, 14]. Another cross-sectional study found that when the child had been ill for two to three years, couples tended to report slightly less marital dissatisfaction, but if the child's illness had progressed for four or more years, marital dissatisfaction tended to increase again [7]. These observations thus justify the importance of longitudinal studies examining relationship adjustment.

Research suggests that what differentiates couples who report positive relationship changes versus deteriorations following a diagnosis of pediatric cancer are: shorter illness duration, mothers' having greater social support, and fathers' belief that they can cope with stress effectively [10]. Psychological distress or mood disturbances were also associated with greater marital distress for both partners two months following 
diagnosis [11], and partners' relationship distress 20-months post diagnosis was predicted by their own depression and their partner's marital dissatisfaction at diagnosis [12]. Marital distress predictors for mothers and fathers may also differ. Whereas mothers' marital distress at 6 and 12-months post diagnosis was associated with her partner's coping at 6 and 12-months (i.e., other-related), fathers' was associated with his own psychological distress and coping near diagnosis (i.e., self-related) [14].

Although the pediatric oncology literature has identified some predictors for marital adjustment, most studies were cross-sectional and used an individual approach. Longitudinal and dyadic studies are scarce and although dyadic studies have been reported in adult cancer settings (e.g., [15-17]), only two dyadic studies have been conducted in the pediatric cancer setting $[18,19]$. In a sample of 22 couples, the first study found, among other results, that a parent's effective communication was related to their partner's perception of greater social support, and perception of greater social support was related to lower anxiety in mothers [18]. In a sample of 150 couples, the second dyadic study found that mothers' disengagement coping strategies were related to fathers' greater depressive symptoms, after controlling for fathers' own coping strategies and sociodemographic variables [19]. Findings from these studies underscore the pertinence of assessing inter-partner effects to enhance our systemic understanding of both parents' adjustment in the context of pediatric cancer. Both of these studies used a cross-sectional design and did not examine marital adjustment, and thus cannot discern how both partner's initial perceptions and adjustment to the illness contribute to their relationship functioning over time.

In the current dyadic longitudinal study, we aimed to determine whether family functioning and parental mood in both partners near the time of diagnosis would predict both partners' marital adjustment 2-years post diagnosis. The Circumplex Model of Marital and Family Systems [20] proposes that two dimensions of family interactions are relevant to understand adaptation. The model has been applied in the context of families of chronically ill children [21]. Cohesion refers to families' emotional bonding and closeness, whereas adaptability refers to their adaptability to change in response to external stressors. Based on this theoretical framework, partners who perceive greater family cohesion and who report greater adaptability (as reflected by lower family stress and individual psychological symptoms, and less problems with changing roles as function of illness) may be less likely to suffer from a spillover effect of the illness stress onto their relationship and may experience better relationship adjustment over time. Supporting this hypothesis, a recent review on parental distress related to childhood cancer revealed that early and intense negative affectivity, as well as family stressors and family weaknesses at the time of diagnosis were among the best predictors of long-term individual distress in parents [3]. We aim to examine whether these results might be extended to marital adjustment. In particular, we predicted that less negative mood states (i.e., less anxiety, depression and fatigue) and better family cohesion (i.e., family cohesion and support) and adaptability (i.e., lower family stress, role ambiguity, role conflict, and role overload) at diagnosis would be associated with better marital adjustment at 2-years post diagnosis in parents of children diagnosed and treated for cancer. Gender differences in these associations were also examined, although no a priori hypotheses were put forward due to the lack of a previous empirical basis. 


\section{Participants and procedure}

\section{Methods}

The current study is a secondary analysis of longitudinal data from the Québec cohort of children with acute lymphoblastic leukemia (QcALL cohort) and their parents $[22,23]$. Children (18 years or less) with acute lymphoblastic leukemia (ALL) who were diagnosed (first occurrence) and treated at the Sainte-Justine University Health Centre, between February 1993 and September 1999, and their parents were consecutively recruited to participate in the longitudinal study (138 families). T1 and T2 assessments were completed just after diagnosis (in average $2.5 \pm 2.5$ weeks ) and two years post diagnosis $(104.3 \pm 2.7$ weeks) $[22,23]$. For the purpose of the present study, couples for whom only one of the two parents provided data were excluded $(n=25)$. Couples who were separated, divorced, or widowed at Times 1 or 2 were also excluded $(n=29)$. The sample consisted of 84 intact couples at diagnosis, resulting in an overall participation rate of $61 \%$. Parents individually completed self-report questionnaires at diagnosis (T1) and 2-years post diagnosis (T2), and were interviewed for demographic information. Only couples for whom data were available for both partners at T2 were included in our analyses, resulting in a final sample of 47 couples. Six couples did not participate at T2 as their child had deceased during the study period. Couples who participated at T1 only ( $n$ $=37$ ) and those who participated at both time points did not significantly differ on any of the medical (child's diagnosis and treatment), sociodemographic (child's gender and age, parents' age and income) or study variables (mood and family well-being) at T1. All couples provided informed consent and the Institutional Review Ethics Board approved the research protocol. Demographic and medical information related to the illness are summarized in Table 1.

\section{Measures \\ Marital adjustment}

The Locke-Wallace Marital Adjustment Test (MAT) [24] is a 15-item scale that has been widely used to measure marital adjustment $[25,26]$. It differentiates between individuals who are well adjusted in their relationship and those who are not. The MAT has excellent psychometric properties $(\alpha=.90)$ [24] and has previously been used with couples of chronically ill children [27]. Global scores range from 2 to 158, with higher scores reflecting better adjustment [24]. A clinical cut-off score of 100 is used to identify significant marital distress [25, 28].

\section{Family functioning}

The Family Well-Being Assessment (FWA) [29] assesses an individual's perception of family well-being on 12 dimensions (74 items), which are assessed on a continuum of well-being to stress. Items are rated on a 6-point Likert scale, with higher scores indicating higher stress on each dimension respectively. The FWA has acceptable psychometric properties, including an excellent reliability coefficient for the total scale $(\alpha$ $=.90$ ) [29] and it is particularly applicable and valid for families with chronically ill children [29]. The choice of subscales included in the current study was based on the Circumplex Model of Marital and Family Systems. Family support and cohesion served as indicators of Family cohesion, whereas family stress, role ambiguity, role conflict, and role overload served as indicators of Family adaptability. Family support refers to the 
extent to which one feels that the family is there to take care of and support him/her $(\alpha=$ .86). Family cohesion refers to the extent to which one feels that one has both personal autonomy and a sense of belonging with the family $(\alpha=.67)$. Family stress refers to feelings of frustration and strain within the family $(\alpha=.80)$. Role ambiguity refers to family members' vague or unclear role expectations $(\alpha=.74)$. Role conflict refers to disputes regarding family members' roles and expectations $(\alpha=.68)$. Role overload refers to one's struggle in reaching role expectations with available resources $(\alpha=.79)$ [29]. To facilitate interpretation, Family support and Family cohesion were reverse-coded for the main analyses so as to reflect the actual label of the subscale (e.g., high scores on family support $=$ higher family support).

\section{Parental mood states}

The Profile of Mood States-Bipolar Form (POMS-BI) [30](72-item) uses adjectives or phrases to describe an individual's mood states in the past week [30]. Items are rated on a 4-point Likert scale $(0=$ much unlike this; $3=$ much like this $)$. Three subscales were selected as being most pertinent in the context of this study: (a) composed-anxious, (b) elated-depressed, and (c) energetic-tired. As per standard practice, raw scores were converted to T-scores [30], and to facilitate interpretation, variables were reverse-coded so as to reflect greater endorsement of the negative aspects (e.g., anxious as opposed to composed). The POMS-BI has good to excellent reliability $(\alpha=.80-.90)$ [31], and test-retest reliabilities for the individual dimensions typically range from .33 to $.72[30]$.

\section{Preliminary analyses}

\section{Statistical analyses}

The distributions of all variables were examined for normality. Non-linear transformations were successfully applied to skewed variables (skew values $>1$ ): marital adjustment was negatively skewed and subjected to a square root transformation, and tiredness was positively skewed and subjected to a logarithmic transformation. All other variables were normally distributed. There was no missing data. A series of paired t-tests and repeated measures ANOVAs and MANOVAs, as well as bivariate correlations were used to initially test the associations between mothers' and fathers' variables, and identify potential control variables among the medical and sociodemographic variables. Means and standard deviations for the study variables are presented in Table 2.

\section{Main analyses}

To assess dyadic associations among family functioning, mood, and marital adjustment in parents, we used the Actor-Partner Interdependence Model (APIM) as our core data analysis strategy (with SPSS MIXED MODELS). The APIM is a modified regression-based technique, which allows for prediction of outcome variables among dyads (see Figure 1) [32]. This multilevel modeling approach has inherent advantages over traditional regression analyses [33]: a) accounting for the non-independence of couple data, b) simultaneously testing both actor effects and partner effects, and c) testing gender differences in the strength of actor and partner effects [32]. An actor effect refers to the effect of an individual's own family functioning and mood on their own marital 
adjustment. A partner effect refers to the effect of an individual's own family functioning and mood on their partner's marital adjustment.

Multilevel linear models were conducted to predict partners' marital adjustment at 2 -years post diagnosis from partners' family functioning and mood scores at diagnosis ( $p$ $<.05)$. Separate models were conducted for each predictor (family functioning and mood variables) at the time of diagnosis. As recommended by Kenny et al. [32], all predictor and outcome variables were standardized prior to conducting these analyses. Partners' predictors (family functioning or mood states) and the error terms for partner's marital adjustment were allowed to correlate to account for the non-independence of partners' scores (see Figure 1 for an example of such a model). To explore potential gender differences, gender and the interaction between gender and predictors were included in all analyses. A significant interaction term indicates a significant gender difference in the strength of an actor or partner effect. All analyses also controlled for mothers' and fathers' marital adjustment at diagnosis.

\section{Preliminary analyses}

\section{Results}

Preliminary descriptive analyses revealed that $25.5 \%$ of mothers and $21.3 \%$ of fathers reported significant marital distress at the time of diagnosis, as indicated by a score below 100 on the MAT. Two years later, $36.2 \%$ of mothers and $42.6 \%$ of fathers met this cut-off. Mothers' and fathers' marital adjustment scores at diagnosis (T1) were positively correlated with their own marital adjustment scores 2-years post diagnosis (T2) (Table S1). Mothers' marital adjustment at diagnosis was also positively associated with fathers' marital adjustment both at diagnosis $(r=.53 p<.001)$ and 2-years post diagnosis $(r=.55, p=.022)$.

Preliminary analyses revealed no significant associations between personal or clinical variables (patient's gender and age, initial diagnosis, number of hospitalisation days, use of radiotherapy, treatment protocol, relapse during the study) or sociodemographic variables (parents' age, personal income, years of education) and marital adjustment. Therefore, none of these variables were controlled in the main analyses. Paired $t$-tests showed that mothers perceived less family cohesion $(t(46)=3.10$, $p=.003)$ than fathers, whereas fathers reported being more tired $(t(46)=2.95, p=.005)$ and perceived more role conflict than mothers $(t(46)=2.05, p=.046)$ at the time of diagnosis. No other gender difference was found on the family well-being, mood or marital adjustment variables.

\section{Main analyses}

Standardised regression coefficients from APIM models for all significant actor, partner, and gender effects are presented in Table 3. All models controlled for T1 marital adjustment. Several actor effects were found. For mothers, increased marital adjustment at T2 was associated with her perception of greater family support, less role conflict, and less role overload at the time of diagnosis. For fathers, increased marital adjustment at T2 was associated with his perception of less role conflict, greater role ambiguity, and being more tired at diagnosis. Significant gender differences were found for all of the aforementioned actor effects, except for role overload, which did not significantly differ between mothers and fathers. As role conflict was a significant predictor in both mothers 
and fathers, the gender difference indicates that this effect was stronger for mothers. One partner effect was found. For fathers, better marital adjustment at T2 was associated with mothers perceiving less role conflict at diagnosis. There was a significant gender difference for this partner effect (Figure 1).

\section{Discussion}

In this dyadic longitudinal study, we examined evolutions of marital adjustment over two years post diagnosis in both parents of children treated for ALL, in relation to their mood and family functioning at the time of diagnosis. An important finding was that positive changes in marital adjustment over time were associated with different characteristics of family functioning and mood for mothers and fathers. We also found that responses of mothers just after diagnosis were also associated with changes in fathers' marital functioning.

In our sample, mothers and fathers reported similar levels of marital adjustment on both occasions. This is coherent with findings from a meta-analysis on parental distress, and family and marital functioning in parents of children with cancer [34]. A substantial portion of parents reported clinically significant marital distress at diagnosis (25.5\% of mothers and $21.3 \%$ of fathers) and this increased over time (36.2\% of mothers and $42.6 \%$ of fathers). These percentages are congruent with findings from other studies of parents in the pediatric cancer context $[11,12]$, and they highlight that marital distress is common in this population, even two years after the initial diagnosis. These findings also underscore the importance of conducting research aimed at better understanding the determinants of relationship adjustment in parents in order to be able to respond to their specific needs in the initial and later stages of the illness.

Significant differences between fathers and mothers were found on family functioning and mood. Overall, these differences were consistent with previous comparisons showing that fathers experience acute gender role conflict during the treatment phase reflected by higher role conflict $[3,18]$. In fact, fathers have reported that the role of economic supporter in the family is often at odds with the emotional support needed by family members [35]. This role conflict may also translate into elevated tired mood levels, as was reflected by the higher levels found in fathers than in mothers.

When exploring longitudinal associations, mothers' increased marital adjustment over time was associated with greater reported family support, less perceived role conflict, and less role overload at the time of diagnosis. This indicates that mothers perceiving that they were supported by their family at diagnosis (i.e., family cohesion) appeared to serve as protective factors for their future marital adjustment, which was not the case in fathers. Conversely, the experience of role conflict after diagnosis, such as perceiving more conflict regarding family roles and their ability to meet these role expectations (i.e., low family adaptability), is related to a deterioration in mothers' marital adjustment over time. Mothers' perception of role conflict and role overload within a family with an ill child may be an additional source of stress which aggravates their initial distress, and could later spill over into their relationship [33]. We found this to be the case to a larger extent in mothers than in fathers. These findings are coherent with the Circumplex Model of Marital and Family Systems as both aspects of cohesion and adaptability appear to play a role in future adjustment [20]. Mothers' marital adjustment was not predicted by their partners' variables, which could indicate that their 
partner's perceived family functioning may not be so relevant for their future marital adjustment. It is possible that their perceived support from the family unit might be sufficient in ensuring that they are well adjusted in their relationship with their partner. This makes sense given that mothers of children with cancer usually seek more social support than fathers [36]. It could also be that patterns of support offered by fathers in the context of their perceived role conflict are not optimal and thus do not translate into mothers' future adjustment [18].

In fathers, associations observed with role conflict are consistent with those observed in mothers. Yet, positive changes in marital adjustment were associated with more role ambiguity. At first sight this may appear counter-intuitive. However, it is very coherent with the fact that fathers may perceive greater role changes following diagnosis. While mothers are typically the primary caregivers to the ill child, fathers are often required to take care of the other children at home and maintain daily routines, which may be unusual tasks for them [36], and mothers are more often at the forefront of the interactions with the hospital. Previous data has suggested that fathers of children with cancer experience considerable gender-role adaptation [18]. Our findings suggest that confronting family roles and reorganizing said roles in the early stages of the illness could strengthen their relationship with their partner over time. Surprisingly, we found that those fathers showing higher fatigue at diagnosis also experienced less marital distress over time. Fathers' fatigue could reflect higher active involvement and supportive behaviours, which would positively impact their perceived relationship later. As reflected in the correlations in Table S1, tiredness was not associated with anxiety or depressed mood and is thus probably not a marker of negative affect here.

Interestingly, beyond their own perception of family functioning, fathers' marital adjustment over time was also predicted by their partners' perception of family functioning. When mothers experienced heightened role conflict around the time of diagnosis, fathers also reported deteriorations in marital adjustment two years later (i.e., partner effect). It is possible that mothers would express dissatisfaction and frustrations, or make demands to have their needs met regarding each parent's role in the family. Such demands may create more relationship conflict and explain fathers' deteriorations in relationship adjustment later. Indeed, the literature on spousal involvement in chronic illness indicates that the unsupportive behaviours exhibited by the spouse appear to be particularly influential in understanding adjustment [37].

Our findings have several implications for clinical research and practice in pediatric oncology. During the treatment of leukemia, it appears that both parents may benefit from interventions targeting role-related burden and stress, for instance by insisting on solving problems raised by multiple role issues, as well as maintaining one's vitality and protecting one's long-term resources. Recent intervention models have addressed such practical problem-solving skills in parents [38]. Interventions stressing family support with mothers also appear to be highly relevant. Intervention models have addressed communication issues and dyadic adjustment in parental couples confronting childhood cancer. Greater awareness that partners might react differently following their child's illness could also potentially lead to greater empathic understanding and support within couples. [39, 40].

We must acknowledge the limitations of the current study. First, our findings reflect the experience of a limited sample of primarily well-adjusted couples from a 
single patient-centered childhood cancer center within the public health system. They may not be representative of highly distressed couples or those with greater financial burden. The high homogeneity of the clinical condition within this sample (pediatric ALL) also limits the transferability of our conclusions to other cancer types and stages. The small sample size may also have reduced statistical power and our ability to detect significant associations among variables. Lastly, although we controlled for baseline marital adjustment in predicting long-term adjustment, the observational nature of this study precludes making any definite conclusions about causation.

To conclude, in a sample of 47 parental couples confronted with childhood leukemia and using the APIM analysis framework, we found independent actor effects in mothers and fathers showing that improvements in perceived marital adjustment were differentially predicted by their perceived family functioning and mood at time of diagnosis. Our findings also support the idea that marital adjustment of fathers over time would partly depend on mothers' initial perceived family functioning. Future studies should further investigate how parents' roles are experienced when they are confronted with childhood cancer as these aspects may influence their marital well-being in the long term. 


\section{References}

1. Vrijmoet-Wiersma, C.M., et al., Assessment of parental psychological stress in pediatric cancer: a review. J Pediatr Psychol, 2008. 33(7): p. 694-706.

2. Long, K.A. and A.L. Marsland, Family adjustment to childhood cancer: a systematic review. Clin Child Fam Psychol Rev, 2011. 14(1): p. 57-88.

3. Sultan, S., et al., A systematic review on factors and consequences of parental distress as related to childhood cancer. Eur J Cancer Care (Engl), 2015.

4. Hutchinson, K.C., et al., Adjustment of caregivers of pediatric patients with brain tumors: a cross-sectional analysis. Psychooncology, 2009. 18(5): p. 515-23.

5. Barrera, M., et al., Differences in mothers' and fathers' psychological distress after pediatric SCT: a longitudinal study. Bone Marrow Transplant, 2012. 47(7): p. 934-939.

6. da Silva, F.M., E. Jacob, and L.C. Nascimento, Impact of childhood cancer on parents' relationships: an integrative review. J Nurs Scholarsh, 2010. 42(3): p. 250-61.

7. Lavee, Y. and M. Mey-Dan, Patterns of change in marital relationships among parents of children with cancer Health \& Social Work, 2003. 28(4): p. 255-263.

8. Brody, A.C. and L.A. Simmons, Family resiliency during childhood cancer: the father's perspective. J Pediatr Oncol Nurs, 2007. 24(3): p. 152-65.

9. Shapiro, J., M. Perez, and M.J. Warden, The Importance of Family Functioning to Caregiver Adaptation in Mothers of Child Cancer Patients: Testing a Social Ecological Model. Journal of Pediatric Oncology Nursing, 1998. 15(1): p. 47-54.

10. Lavee, Y., Correlates of change in marital relationships under stress: The case of childhood cancer. Families in Society: The Journal of Contemporary Social Services, 2005. 86(1): p. 112-120.

11. Dahlquist, L.M. and D.I. Czyzewski, Parents of children newly diagnosed with cancer: Anxiety, coping, and marital distress. J of Pediatric Psychology 1993. 18(3): p. 365-376.

12. Dahlquist, L.M., D.I. Czyzewski, and C.L. Jones, Parents of children with cancer: $A$ longitudinal study of emotional distress, coping style, and marital adjustment two and twenty months after diagnosis. J of Pediatric Psychology, 1996. 21(4): p. 541-554.

13. Yeh, C.H., Gender differences of parental distress in children with cancer. Journal of Advanced Nursing, 2002. 38(6): p. 598-606.

14. Hoekstra-Weebers, J.E.H.M., et al., Marital dissatisfaction, psychological distress, and coping of parents of pediatric cancer patients Journal of Marriage and Family, 1998. 60(4): p. 1012-1021.

15. Moser, M.T., et al., Higher emotional distress in female partners of cancer patients: prevalence and patient-partner interdependencies in a 3-year cohort. Psycho-Oncology, 2013. 22(12): p. 2693-2701.

16. Manne, S. and H. Badr, Intimacy processes and psychological distress among couples coping with head and neck or lung cancers. Psycho-Oncology, 2010. 19(9): p. 941-954.

17. Lafaye, A., et al., Dyadic effects of coping strategies on emotional state and quality of life in prostate cancer patients and their spouses. Psycho-Oncology, 2014. 23(7): p. 797-803.

18. Hall, J.A., An exploratory study of communication, gender-role conflict, and social support of parents of children treated at children's hospital. J Psychosoc Oncol, 2010a. 28(5): p. 511-25.

19. Compas, B.E., et al., Mothers and Fathers Coping With Their Children's Cancer: Individual and Interpersonal Processes. Health Psychology, 2015: p. 1-11.

20. Olson, D.H., C.S. Russell, and D.H. Sprenkle, Circumplex model of marital and family systems: VI. Theoretical update. Family process, 1983. 22(1): p. 69-83. 
21. Kazak, A.E., Families of chronically ill children: a systems and social-ecological model of adaptation and challenge. Journal of consulting and clinical psychology, 1989. 57(1): p.

25.

22. Marcoux, S., et al., Predictive factors of internalized and externalized behavioral problems in children treated for acute lymphoblastic leukemia. Pediatric blood \& cancer, 2012. 58(6): p. 971-977.

23. Marcoux, S., et al., Role of NOS3 DNA Variants in Externalizing Behavioral Problems Observed in Childhood Leukemia Survivors. Journal of Pediatric Hematology/Oncology, 2013. 35(4): p. e157-e162.

24. Locke, H.J. and K.M. Wallace, Short marital-adjustment and prediction tests: Their reliability and validity. Marriage and family living, 1959: p. 251-255.

25. Reese, J.B., et al., Pain and functioning of rheumatoid arthritis patients based on marital status: is a distressed marriage preferable to no marriage? The Journal of Pain, 2010. 11(10): p. 958-964.

26. Woloski-Wruble, A.C., et al., Israeli and Chinese partners of women with breast cancer: a cross-cultural view of marital issues. Psycho-Oncology, 2012. 21(3): p. 324-331.

27. Alderfer, M.A., et al., Evidence-based assessment in pediatric psychology: family measures. J Pediatr Psychol, 2008. 33(9): p. 1046-61; discussion 1062-4.

28. Cano, A., et al., Marital functioning, chronic pain, and psychological distress. Pain, 2004. 107(1): p. 99-106.

29. Caldwell, S., Measuring family well-being: Conceptual model, reliability, validity, and use. Measurement of Nursing Outcomes: Measuring Client Outcomes. Springer Publishing: New York, 1988: p. 396-416.

30. Lorr, M., D. McNair, and J. Heuchert, Profile of mood states: bipolar supplement. North Tonawanda, New York: Multi-Health Systems, Ine, 2003.

31. O'Halloran, P.D., G.C. Murphy, and K.E. Webster, Reliability of the bipolar form of the Profile of Mood States using an altenative test protocol. Psychological reports, 2004. 95(2): p. 459-463.

32. Kenny, D.A., D.A. Kashy, and W.L. Cook, Dyadic data analysis. 2006, New York: Guilford.

33. Hall, J.A., Parents' networks: Egocentric networks and unique and shared sources of social support. Connections, 2010b. 30(2): p. 41-49.

34. Pai, A.L., et al., A meta-analytic review of the influence of pediatric cancer on parent and family functioning. J Fam Psychol, 2007. 21(3): p. 407-15.

35. McNeill, T., Fathers of Children with a Chronic Health Condition Beyond Gender Stereotypes. Men and Masculinities, 2007. 9(4): p. 409-424.

36. Goldbeck, L., Parental coping with the diagnosis of childhood cancer: gender effects, dissimilarity within couples, and quality of life. Psychooncology, 2001. 10(4): p. 325-35.

37. Manne, S.L., et al., Partner unsupportive responses, avoidant coping, and distress among women with early stage breast cancer: patient and partner perspectives. Health Psychology, 2005. 24(6): p. 635.

38. Sahler, O.J., et al., Using problem-solving skills training to reduce negative affectivity in mothers of children with newly diagnosed cancer: report of a multisite randomized trial. J Consult Clin Psychol, 2005. 73(2): p. 272-83.

39. Kazak, A.E., et al., Feasibility and preliminary outcomes from a pilot study of a brief psychological intervention for families of children newly diagnosed with cancer. Journal of Pediatric Psychology, 2005. 30(8): p. 644-655. 
40. Li, Q. and A.Y. Loke, A systematic review of spousal couple-based intervention studies for couples coping with cancer: direction for the development of interventions. PsychoOncology, 2014. 23(7): p. 731-739. 
Table 1. Sample description ( $n=47$ couples $)$

\begin{tabular}{|c|c|c|}
\hline Child's characteristics & M (SD) or N (\%) & \\
\hline Age at diagnosis, years & $5.92(4.10)$ & \\
\hline $\begin{array}{l}\text { Length of initial hospitalization } \\
\text { (days) }\end{array}$ & $30.51(8.58)$ & \\
\hline \multicolumn{3}{|l|}{ Sex of child } \\
\hline Boys & $31(66.0)$ & \\
\hline Girls & $16(34.0)$ & \\
\hline \multicolumn{3}{|l|}{ ALL risk status } \\
\hline Standard risk & $20(42.6)$ & \\
\hline High risk & $27(57.4)$ & \\
\hline \multicolumn{3}{|l|}{ Treatment protocol } \\
\hline DFCI 91-01 & $19(40.4)$ & \\
\hline DFCI 95-01 & $28(59.6)$ & \\
\hline \multicolumn{3}{|l|}{ Cranial radiation therapy } \\
\hline No & $10(21.3)$ & \\
\hline Yes & $37(78.7)$ & \\
\hline \multicolumn{3}{|l|}{ Relapse during the study } \\
\hline No & $43(91.5)$ & \\
\hline Yes & $4(8.5)$ & \\
\hline Parents' characteristics & $\begin{array}{c}\text { Mothers } \\
\text { M (SD) or N }(\%)\end{array}$ & $\begin{array}{c}\text { Fathers } \\
\text { M (SD) or } \mathbf{N}(\%)\end{array}$ \\
\hline Age at diagnosis, years & $34.23(4.64)$ & $36.95(5.46)$ \\
\hline Years of education & $13(2.22)$ & $13(2.93)$ \\
\hline \multicolumn{3}{|l|}{ Financial income, at diagnosis } \\
\hline Not applicable & $3(7.3)$ & $0(0.0)$ \\
\hline$<29,999$ & $27(65.9)$ & $16(39.0)$ \\
\hline $30,000-49,999$ & $11(26.8)$ & $17(41.5)$ \\
\hline$\geq 50,000$ & $0(0.0)$ & $8(19.5)$ \\
\hline Number of children living at home & \multicolumn{2}{|c|}{$1.83(2.22)$} \\
\hline
\end{tabular}


Table 2. Means (standard deviations) for marital adjustment, family functioning, and mood variables for mothers and fathers.

\begin{tabular}{lcc}
\hline Variable & Mothers & Fathers \\
\hline Marital adjustment & & \\
$\quad$ Marital adjustment (T1) & $114.21(21.38)$ & $112.70(26.02)$ \\
$\quad$ Marital adjustment (T2) & $104.38(30.34)$ & $103.28(27.78)$ \\
Family functioning (T1) & & \\
$\quad$ Family stress & $2.83(1.14)$ & $2.91(1.10)$ \\
Family support & $2.29(1.00)$ & $2.38(.81)$ \\
Family cohesion & $\mathbf{2 . 1 5}(. \mathbf{8 1})$ & $\mathbf{2 . 4 9}(\mathbf{. 7 1})$ \\
Role conflict & $\mathbf{2 . 7 0 ( 1 . 0 2 )}$ & $\mathbf{2 . 9 8}(.96)$ \\
Role overload & $2.77(1.29)$ & $2.58(.93)$ \\
Role ambiguity & $1.89(.75)$ & \\
Mood (T1) & & \\
Anxious mood & $50.26(9.81)$ & $48.89(9.59)$ \\
Depressed mood & $53.02(10.46)$ & $\mathbf{4 5}(11.77)$ \\
Tired mood & $\mathbf{5 0 . 4 7 ( 1 0 . 5 6 )}$ & $\mathbf{4 5 . 3 6 ( 6 . 0 5 )}$ \\
\hline
\end{tabular}

Note. Higher scores on the marital adjustment variable indicate better adjustment. Family functioning variables are scored on a continuum of well-being to stress, with higher scores indicating higher stress on each dimensions respectively. Lower scores on the mood variables indicate greater endorsement of the negative mood (anxious, depressed, and tired, respectively). Bolded means indicate significant gender differences. 
Table 3. Summary of actor, partner and gender effects as identified by APIM models predicting marital adjustment at 2-years post diagnosis with family functioning and parental mood states at diagnosis.

\begin{tabular}{|c|c|c|c|c|c|c|}
\hline & & Actor effect & & Partr & effect & \\
\hline $\begin{array}{l}\text { Predictors } \\
\text { (at diagnosis) }\end{array}$ & Father & Mother & $\begin{array}{c}\text { Gender } \\
\text { difference }\end{array}$ & Father & Mother & $\begin{array}{c}\text { Gender } \\
\text { difference }\end{array}$ \\
\hline Family support & & $\beta=.487$ & $p=.021$ & & & \\
\hline Role conflict & $\beta=-.341$ & $\beta=-.505$ & $p<.001$ & $\beta=-.474$ & & $p=.022$ \\
\hline Role overload & & $\beta=-.366$ & $p=.131$ & & & \\
\hline Role ambiguity & $\beta=.445$ & & $p<.001$ & & & \\
\hline Tired & $\beta=.383$ & & $p=.009$ & & & \\
\hline
\end{tabular}

Note. Family support, Family cohesion, Role conflict, Role overload, and Role ambiguity were measured with the FWA. Tired was measured with the POMS-BI. To facilitate interpretation here, Family support and Tired mood were reverse-coded so as to reflect the actual label of the subscale (e.g., high scores on family support $=$ higher family support). All analyses controlled for mothers' and fathers' marital adjustment at diagnosis. For clarity, only significant regression coefficients are displayed. 


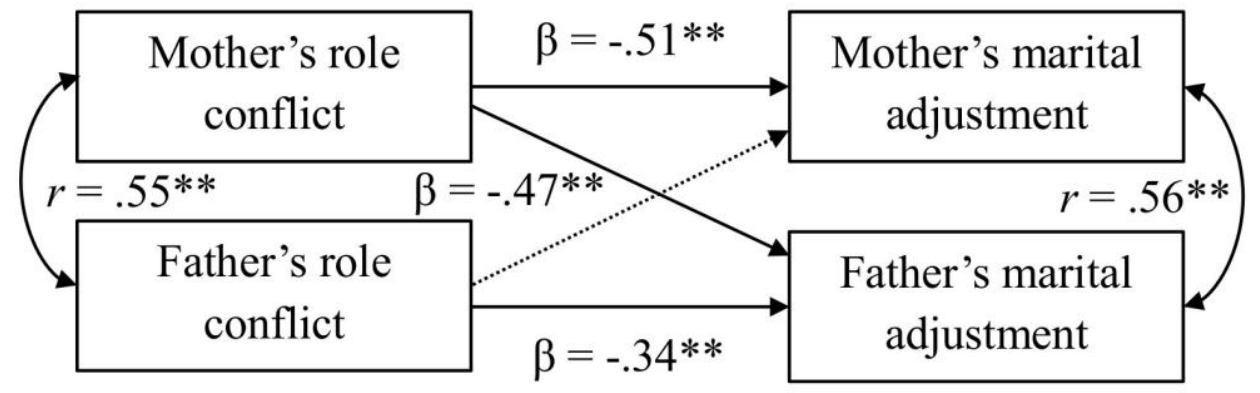

Note. ${ }^{* *} \mathrm{p}<.01,{ }^{*} \mathrm{p}<.05$; the dashed line represents a non-significant association.

Figure 1. Actor-partner interdependence model (APIM) predicting marital adjustment at 2-years post diagnosis from role conflict at diagnosis ( $n=47$ couples). 
Table S1. Correlations between variables for mothers and fathers at diagnosis (T1) and 2-years post diagnosis (T2)

\begin{tabular}{|c|c|c|c|c|c|c|c|c|c|c|c|}
\hline & 1 & 2 & 3 & 4 & 5 & 6 & 7 & 8 & 9 & 10 & 11 \\
\hline 1. Marital adjustment (T1) & $.53^{* *}$ & $.51^{* * *}$ & -.24 & $.54 * *$ & $.56^{* *}$ & $-.36^{*}$ & -.24 & $-.31 *$ & -.08 & .13 & -.27 \\
\hline 2. Marital adjustment (T2) & $.48^{* *}$ & $.55^{* *}$ & $-.28 *$ & $.62 * *$ & $.47 * *$ & $-.32 * *$ & $-.52 * *$ & $-.38 * *$ & -.006 & .16 & -.26 \\
\hline 3. Family stress (T1) & -.10 & -.01 & $.53 * *$ & $-.41 * *$ & $-.43 * *$ & $.47 * *$ & $.33^{*}$ & .05 & $.44 * *$ & -.23 & -.15 \\
\hline 4. Family support (T1) & $-.32 *$ & .15 & -.23 & $.53^{* *}$ & $.63 * *$ & $-.74 * *$ & $-.53 * *$ & $-.51 * *$ & -.12 & .27 & -.27 \\
\hline 5. Family cohesion (T1) & $.48^{* *}$ & .10 & $-.48 * *$ & $.42 * *$ & $.59 * *$ & $.64 * *$ & $-.53 * *$ & $-.50 * *$ & .02 & .03 & -.27 \\
\hline 6. Role conflict (T1) & $-.36^{*}$ & -.05 & $.42 * *$ & $-.38 * *$ & $-.58 * *$ & $.56^{* *}$ & $.58 * *$ & $.52 * *$ & -.09 & .21 & .13 \\
\hline 7. Role overload (T1) & $-.36^{*}$ & -.24 & $.39 * *$ & $-.29 *$ & $-.61 * *$ & $.62 * *$ & $.52 * *$ & $.60 * *$ & -.19 & -.06 & .11 \\
\hline 8. Role ambiguity ( $\mathrm{T} 1$ ) & $-.36^{*}$ & .24 & .13 & $-.45 * *$ & $-.41 * *$ & $.54 * *$ & $.33^{*}$ & .14 & .16 & .07 & .20 \\
\hline 9. Anxious mood (T1) & .04 & -.02 & -.04 & -.11 & -.04 & -.14 & .00 & -.10 & -.04 & $.43 * *$ & .14 \\
\hline 10. Depressed mood (T1) & -.27 & -.05 & .07 & $-.30^{*}$ & -.26 & .20 & .15 & $.29 *$ & .26 &. .03 & .08 \\
\hline 11. Tired mood (T1) & .06 & $.34 *$ & .01 & .10 & .15 & -.03 & -.03 & .03 & -.05 & -.11 & .09 \\
\hline
\end{tabular}

Note. Mothers' bivariate correlations are above the diagonal and fathers' bivariate correlations are below the diagonal. Interrelationships between the partners' variables are displayed on the diagonal. $* * p<.01, * p<.05$ 